\title{
LIQUID-LIQUID EQUILIBRIA FOR THE SYSTEM COMPOSED BY WATER, ACETIC ACID, AND 1-HEXANOL AT 293.15 K AND UNDER ATMOSPHERIC PRESSURE USING REFRACTOMETRY AND DENSITOMETRY
}

\author{
HOMRICH, P.O.B. CERIANI, R.
}

Universidade Estadual de Campinas, Faculdade de Engenharia Química, Departamento de

Desenvolvimento de Processos e Produtos

E-mail para contato: rceriani@feq.unicamp.br

\begin{abstract}
In order to evaluate the accuracy of an indirect quantification method, the liquid-liquid equilibrium for the ternary system composed by water, acetic acid and 1-hexanol at $293.15 \mathrm{~K}$ and at atmospheric pressure was determined by means of refractometry and densitometry. The binodal curve was measured using the cloud point method, while the tie-lines were obtained in a cell-glass where the mixture was vigorously stirred and maintained at constant temperature. After the completeness of phase separation, samples were collected using simple syringe needles and the concentration of all components were satisfactorily obtained using the relation between the refraction index and density with the binodal curve sample concentrations. Generated data were correlated using NRTL model, and their quality were verified by Othmer-Tobias and Hand tests. All the results were compared with a previous work which quantified the equilibrium phases by means of a direct method (gas-chromatographic analysis). The indirect method were very efficient, resulting in two equations that related the physical properties with sample concentrations with an average relative deviations between the experimental and calculated physical properties lower than $0.01 \%$. NRTL model parameters were regressed and the mean deviation was 0.61. Othmer-Tobias and Hand tests presented coefficients of determination of 0.9984 and 0.9975 , indicating the high quality of these data.
\end{abstract}

\section{INTRODUCTION}

In order to separate a component of interest from a liquid mixture, the liquid extraction technique is widely used by the chemical industry. This type of separation is present in various processes, such as the removal of high boiling organic compounds from wastewater, product recovery from reactions, in the refining of oils and in solvent concentration (Kubota and Masahiro, 2006; Stoicescu et al., 2008; Rodrigues et al., 2007; Liu et al., 2014; Senol, 2013). In order to design a liquid extractor equipment and to optimize the separation process, the solubility behavior of the mixture components must be known precisely, and the thermodynamic modeling of the system must be determined (Lo and Baird, 2001; Juang et al., 
1997). One of the step of these procedures is the quantification of the extracted and refined phases. With these data, it is possible to determine some process factors, such as the solvent selectivity and the partition coefficient (Geankoplis, 2003; Stevens et al., 2007). Usually, direct methods are used to obtain the concentrations of the phases in equilibrium, like gas chromatography. When direct methods are expansive, concentrations can be determined by indirect methods. In the case of liquid-liquid equilibria, by correlating the concentration of each component in a mixture that lies on the binodal curve with a chemical or physical property, one can posteriorly obtain the concentration of the extracted and refined phases in equilibrium. This procedure is widely used in quantification for a variety of systems, like polymers, ionic liquids, methyl esters, alcoholic systems and so on (Almeida et al., 2012; Batistell et al., 2011; Taha et al., 2012; Rocha et al., 2014). In general, as differences among pure component properties increase, accuracy of the indirect method increases. Calibration curves of some properties like refraction index, density, speed of sound, spectrophotometry, viscosity and others, can be related with mass concentration of the samples obtained at the binodal curve by the cloud point method.

This paper aimed to compare the phase quantification between indirect methods, i.e., refractometry and densitometry, with a direct method, i.e., gas chromatography (Senol, 2004). For this purpose, binodal curve was determined through the cloud point method and related with the two physical properties investigated in this study. The tie-line data were modelled using NRTL model (Renon and Prausnitz, 1968), and their quality were verified by OthmerTobias (Othmer and Tobias, 1942) and Hand (Hand, 1930) tests.

\section{MATERIALS AND METHODS}

\subsection{Materials}

Acetic acid was purchased from Sigma Aldrich with a purity of $99.7 \%$. 1-Hexanol was also provided by Sigma Aldrich and presented $99 \%$ of purity. Distilled water was used in the experiments. Table 1 presents the physical properties density $(\rho)$ and refraction index $(n D)$ of the components measured using a refractometer (RE 40D, Mettler-Toledo) and a densimeter (DMA 5000, Anton Paar), at the temperature of experiments (293.15 K) and at the temperature of the calibration curves $(298.15 \mathrm{~K})$. Note that the differences among measured values at these two temperatures for each compound were lower than $0.5 \%$.

Table 1 - Physical properties (density and refraction index), at 293.15 and 298.15 for the pure components.

\begin{tabular}{|c|c|c|c|c|}
\hline Component & $\rho^{293.15^{\circ} \mathrm{C}}\left[\mathrm{g} / \mathrm{cm}^{3}\right]$ & $\mathrm{nD}^{293.15^{\circ} \mathrm{C}}$ & $\rho^{298.15^{\circ} \mathrm{C}}\left[\mathrm{g} / \mathrm{cm}^{3}\right]$ & $\mathrm{nD}^{298.15^{\circ} \mathrm{C}}$ \\
\hline 1: Water & 0.99821 & 1.3325 & 0.99708 & 1.3300 \\
\hline 2: Acetic Acid & 1.05127 & 1.3724 & 1.04566 & 1.3703 \\
\hline 3: 1-Hexanol & 0.81860 & 1.4180 & 0.81506 & 1.4161 \\
\hline
\end{tabular}

\subsection{Experimental procedure}




\subsubsection{Binodal curve and calibration curves}

The binodal curve was determined by the cloud point method. In a cell glass, homogeneous binary systems (water/ acetic acid and ethanol/ acetic acid) of known mass concentrations were prepared using an analytical balance (AS 220/C/2, Radwag), accurate to $0.0001 \mathrm{~g}$, and stirred vigorously using a magnetic stirrer. System temperature was maintained constant at $293.15 \pm 0.1 \mathrm{~K}$ with a thermostatic bath (Viscotherm VT2, Anton Paar GmbH). The third component was added in the solution using an automatic burette (Dosimat 715, Metrohm) until the system turbidity occurred. Then, for each drop of the third compound added, the mixture remained stirring for approximately five minutes, and then agitation was paused allowing the transparency/turbidity identification. At this time, a cloudy sample was collected and injected using simple syringes in the refractometer and in the densimeter subsequently. Each sample was analyzed in triplicates at $298.15 \mathrm{~K}$, i.e., $5 \mathrm{~K}$ above the equilibrium temperature, to ensure that sample was homogeneous and isotropic. In this way, phase splitting was avoided during measurements in the refractometer and densimeter. Calibration curves at $298.15 \mathrm{~K}$ are commonly used for quantification of isobaric vapor-liquid equilibria (Yu et al., 2000).

\subsubsection{Tie-lines measurement and thermodynamic correlation}

Tie-lines were measured by preparing mixtures with mass concentration within the diagram region delimited by the binodal curve, to ensure phase split. Ternary mixtures were agitated vigorously with a magnetic stirrer for 3 hours in an equilibrium glass cell. Then, the system rested for a period of 12 hours, allowing the completeness of the phase split, regarded by a clean and well defined phase boundary between the phases. Samples were collected using syringes and analyzed in the densimeter and the refractometer.

Generated data for the tie lines in terms of concentrations of each compounds in the two phases in equilibrium were adjusted using the NRTL model. Equation 1 presents the relation between the activity coefficient of component $i$ with its mass concentration on the phase $\alpha$ presented by NRTL model.

$$
\begin{aligned}
& \ln \gamma_{i}^{\alpha}=\frac{\sum_{j}^{C} \tau_{j i} G_{j i} x_{j}}{\sum_{k}^{C} G_{k i} x_{k}}+\sum_{j=1}^{C}\left[\frac{x_{j} G_{i j}}{\sum_{k}^{n} G_{k j} x_{k}}\left(\tau_{i j}-\frac{\sum_{r}^{C} \tau_{r i} G_{r j} x_{k}}{\sum_{k}^{C} G_{k j} x_{k}}\right)\right] \\
& G_{i j}=\exp \left(-\alpha_{i j} \tau_{i j}\right) \\
& \tau_{i j}=\frac{A_{i j}}{T} \\
& \alpha_{i j}=\alpha_{j i}
\end{aligned}
$$


where: $\gamma_{i}^{\alpha}$ : activity coefficient of component $i$ in phase $\alpha ; x$ : molar fraction; Aij e Aji: adjustable parameters to the experimental data; $\alpha i j$ e $\alpha j i$ : parameter of the non randomness of the mixture.

The mean deviation between the experimental and calculated compositions were determined through Equation 5.

$$
\delta x=100 \sqrt{\frac{\sum_{i}^{M} \sum_{j}^{N}\left\{\left(x_{i j k}^{I, \exp }-x_{i j k}^{I, c a l c}\right)^{2}+\left(x_{i j k}^{I I, \exp }-x_{i j k}^{I I, c a l c}\right)^{2}\right\}}{2 M N}}
$$

where: $M$ : number of tie-lines; $N$ : number of components.

\section{RESULTS}

\subsection{Binodal curve and calibration curves}

Table 2 presents the experimental data for cloud points for the system water (1), acetic acid (2) and 1-hexanol (3) at $293.15 \mathrm{~K}$. The refraction indexes and densities of the binodal curve mixtures measured at $298.15 \mathrm{~K}$ are also shown.

Table 2 - Cloud point for the aqueous and organic phase at $293.15 \mathrm{~K}$, refraction index and density at $298.15 \mathrm{~K}$.

\begin{tabular}{|l|c|c|c|c|c|c|c|c|c|c|c|}
\hline \multicolumn{9}{|c|}{ Aqueous Phase } \\
\hline $100 \mathrm{w}_{1}$ & $100 \mathrm{w}_{2}$ & $\mathrm{nD}$ & $\sigma\left(\times 10^{5}\right)$ & $\rho\left[\mathrm{g} / \mathrm{cm}^{3}\right]$ & $\sigma^{\mathrm{a}}\left(\times 10^{5}\right)$ & $100 \mathrm{w}_{1}$ & $100 \mathrm{w}_{2}$ & $\mathrm{nD}$ & $\sigma^{\mathrm{a}}\left(\times 10^{5}\right)$ & $\rho\left[\mathrm{g} / \mathrm{cm}^{3}\right]$ & $\sigma^{\mathrm{a}}\left(\times 10^{5}\right)$ \\
\hline 99.15 & 0.00 & 1.3332 & 0.000 & 0.99735 & 8.340 & 6.57 & 0.00 & 1.4098 & 4.71 & 0.83026 & 8.219 \\
\hline 96.15 & 2.97 & 1.3349 & 0.000 & 1.00127 & 4.546 & 7.08 & 2.02 & 1.4087 & 0.00 & 0.83458 & 26.242 \\
\hline 90.15 & 8.89 & 1.3389 & 0.000 & 1.00961 & 5.354 & 7.79 & 6.30 & 1.4065 & 0.00 & 0.84456 & 9.031 \\
\hline 85.53 & 13.4611 .3414 & 4.714 & 1.01486 & 8.957 & 9.33 & 10.12 & 1.4045 & 4.71 & 0.85475 & 10.339 \\
\hline 78.97 & 19.87 & 1.3458 & 0.000 & 1.02245 & 7.040 & 11.17 & 15.83 & 1.4014 & 4.71 & 0.86882 & 9.393 \\
\hline 70.01 & 28.34 & 1.3513 & 0.000 & 1.03187 & 9.092 & 14.64 & 22.90 & 1.3974 & 0.00 & 0.88876 & 18.409 \\
\hline 64.87 & 33.13 & 1.3562 & 4.714 & 1.03736 & 5.735 & 17.35 & 27.28 & 1.3948 & 4.71 & 0.90234 & 8.042 \\
\hline 57.60 & 37.41 & 1.3603 & 0.000 & 1.04272 & 7.789 & 22.04332 .05 & 1.3910 & 4.71 & 0.92040 & 13.736 \\
\hline 52.18 & 40.12 & 1.3641 & 4.714 & 1.04635 & 16.540 & 27.91 & 35.15 & 1.3872 & 0.00 & 0.93766 & 18.373 \\
\hline 43.91 & 42.02 & 1.3687 & 0.000 & 1.04845 & 14.197 & 32.57 & 38.01 & 1.3839 & 4.71 & 0.95149 & 16.310 \\
\hline
\end{tabular}

Relationships between the concentrations of each compound in the mixture and the physical properties shown in Table 2 were adjusted with a linear function or a second order polynomial. By analyzing the better coefficients of determination among these correlations, water and acetic acid were selected. Then two quadratic functions (Equations 6 and 7) were generated for relating density and refraction index with the mass concentration of water $\left(w_{1}\right)$ and acetic acid $\left(w_{2}\right)$, according to Rocha (2014). 


$$
\begin{aligned}
& n D=1.4062+0.0647 w_{1}-0.14 w_{1}^{2}-0.056 w_{2}+0.0123 w_{2}^{2}-0.0823 w_{1} w_{2} \\
& \rho=0.8978-1.0803 w_{1}+1.197 w_{1}^{2}+0.3014 w_{2}+0.3923 w_{2}^{2}+0.961 w_{1} w_{2}
\end{aligned}
$$

The equations 6 and 7 presented an average relative deviation of 0.036 and $0.48 \%$ for the refraction index and density functions, respectively, and their coefficient of determination were 0.9996 and 0.996 . These two equations were used to quantify concentration of the extract and raffinate phases in the tie-line measurement.

\subsection{Tie-lines measurement and thermodynamic modelling}

To obtain the tie-lines, six samples with their mass concentrations within the binodal curve were prepared, and after phase splitting, refraction index and the density were measured for each phase. The measured values of each physical property was equaled to Equations 6 and 7 , and the mass concentrations of water and acetic acid calculated. Mass concentration of 1hexanol was obtained by difference. Table 3 presents the overall concentration, the physical properties of the two phases and their standard deviations, as well as the concentrations calculated by the indirect method.

Table 3 - Overall composition of the mixture, physical properties of the aqueous and organic phase with their mass fraction determined by equation 3 and 4 .

\begin{tabular}{|c|c|c|c|c|c|c|c|c|c|c|c|c|c|c|}
\hline $\begin{array}{c}\text { Overall } \\
\text { composition }\end{array}$ & \multicolumn{1}{|c|}{ Aqueous Phase } \\
\hline $100 w_{1} \mathrm{a}^{\mathrm{a}}$ & $100 w_{2} \mathrm{a}$ & $\mathrm{nD}$ & $\sigma\left(\times 10^{5}\right)$ & $\rho\left[\mathrm{g} / \mathrm{cm}^{3}\right]$ & $\sigma\left(\times 10^{5}\right)$ & $100 \mathrm{w}_{1}^{\mathrm{a}}$ & $100 \mathrm{w}_{2}^{\mathrm{a}}$ & $\mathrm{nD}$ & $\sigma\left(\times 10^{5}\right)$ & $\rho\left[\mathrm{g} / \mathrm{cm}^{3}\right]$ & $\sigma\left(\times 10^{5}\right)$ & $100 \mathrm{w}_{1^{\mathrm{a}}}$ & $100 \mathrm{w}_{2^{\mathrm{a}}}$ \\
\hline 45.03 & 5.04 & 1.3374 & 0.000 & 1.00616 & 8.287 & 92.15 & 7.19 & 1.4072 & 4.714 & 0.84074 & 5.099 & 7.79 & 5.01 \\
\hline 40.22 & 10.01 & 1.3401 & 4.714 & 1.011347 & 13.888 & 87.80 & 11.70 & 1.4052 & 4.714 & 0.84543 & 5.793 & 9.65 & 9.45 \\
\hline 35.28 & 14.95 & 1.3442 & 4.714 & 1.018913 & 6.549 & 81.46 & 17.91 & 1.4022 & 4.714 & 0.85633 & 8.731 & 12.13 & 15.08 \\
\hline 30.18 & 19.98 & 1.3480 & 4.714 & 1.025537 & 24.513 & 75.73 & 23.15 & 1.3995 & 0.000 & 0.87136 & 18.385 & 14.06 & 19.79 \\
\hline 25.03 & 25.04 & 1.3525 & 0.000 & 1.034157 & 6.799 & 68.95 & 28.96 & 1.3968 & 4.714 & 0.89152 & 28.004 & 15.40 & 24.19 \\
\hline 43.27 & 32.33 & 1.3576 & 4.714 & 1.040267 & 9.534 & 61.59 & 34.40 & 1.3932 & 0.000 & 0.91348 & 22.226 & 19.06 & 29.64 \\
\hline
\end{tabular}

Data shown in Table 3 were correlated with NRTL model using an algorithm based on maximum likelihood proposed by Stragevitch and D’Avila (1997). The regressed parameters are presented in Table 4.

Table 4 - Regressed parameters for NRTL model for water (1), acetic acid (2) and 1-hexanol (3) at $293.15 \mathrm{~K}$.

\begin{tabular}{|c|c|c|c|}
\hline Pair & $A i j / K$ & $A j i / K$ & $\alpha i j$ \\
\hline 12 & -0.18091 & -257.99 & 0.21918 \\
\hline 13 & 2094.0 & 124.75 & 0.25258 \\
\hline 23 & 113.83 & -656.16 & 0.34000 \\
\hline
\end{tabular}

Experimental data for binodal curve and tie-lines together with NRTL model are presented in Figure 1. It is also shown experimental data from Senol (2004). 


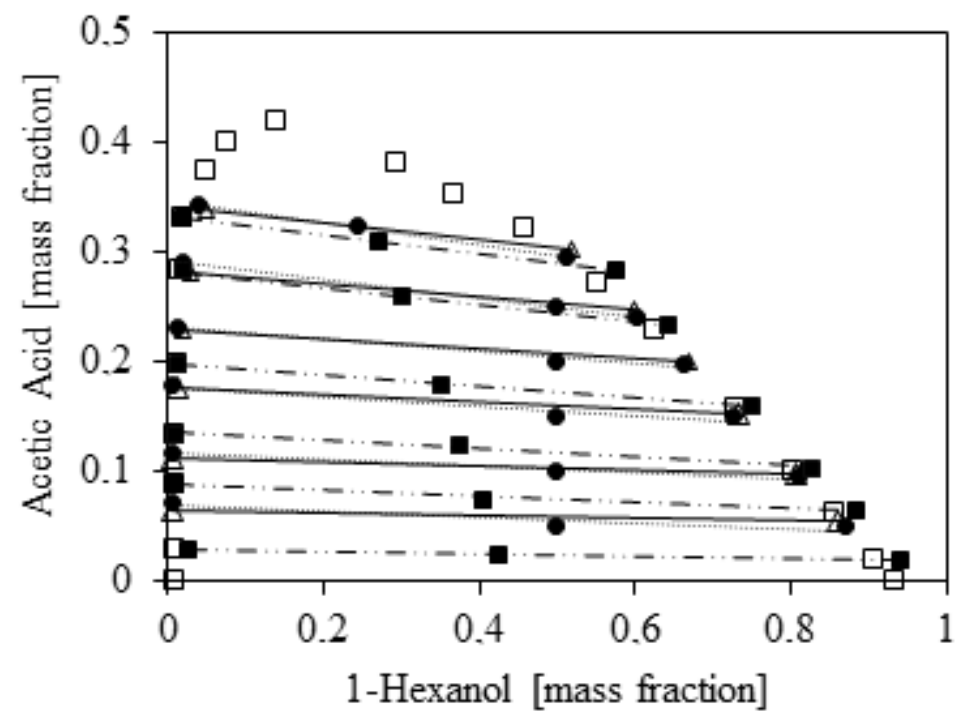

Figure 1 - Phase equilibrium diagram of the system water (1), acetic acid (2) and 1-hexanol (3) at 293.15 K. Legend: ○ binodal curve; $(\bullet-)$ experimental tie-lines; $(\Delta \ldots)$ NRTL tielines; ( - -....) experimental tie-lines from Senol (2004).

As can be observed in Figure 1, the indirect quantification of the ternary system showed accurate concentration for both aqueous and organic phases, since the filled black points coincided with the binodal curve. Also, it is possible to verify that the NRTL model satisfactorily correlated the experimental data, resulting in a mean deviation of $0.61 \%$. From Figure 1, one can compare the results obtained from the direct method with those obtained in this study, and it is possible to verify that the indirect method presented a more precise result than the quantification accomplished through gas chromatography.

In order to verify the quality of data presented in this work, mass concentrations in both phases were related by the Othmer-Tobias and Hand tests. Figure 2 shows the linear correlations obtained.
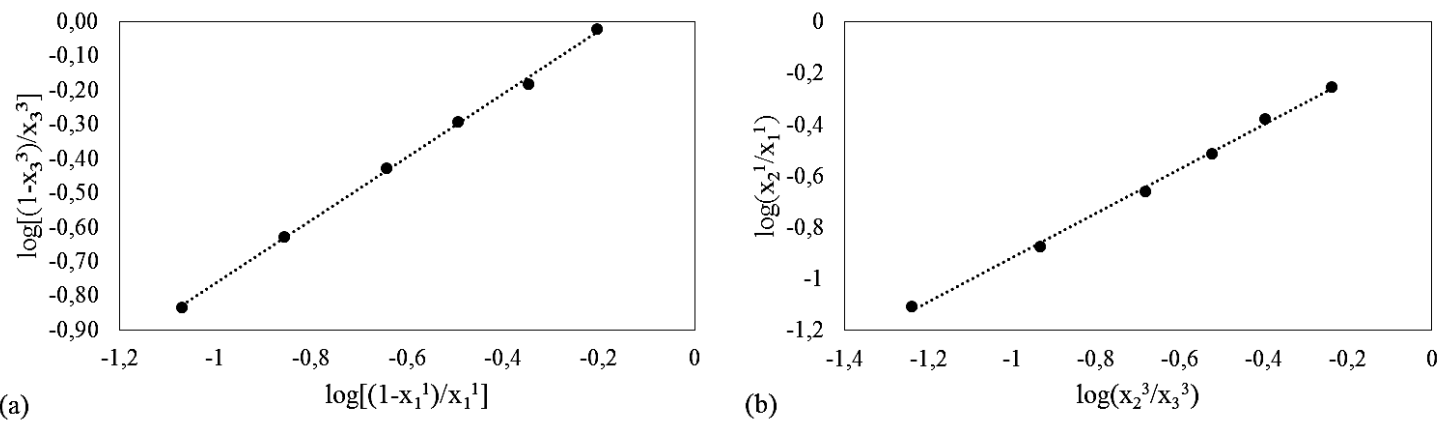

Figure 2 - Quality tests for water (1), acetic acid (2) and 1-hexanol (3): (a) Othmer-Tobias method; (b) Hand method. Legend: $\mathrm{x}_{i}^{\mathrm{j}}$ : molar fraction of component $\mathrm{i}$ present in the phase rich in component $\mathrm{j}$. 
Figure 2 indicates that the experimental data obtained for the system using the indirect method have a very good quality, with coefficients of determination of 0.9984 and 0.9975 for the Othmer-Tobias and Hand tests, respectively.

\section{CONCLUSION}

The liquid-liquid equilibrium data for the system water, acetic acid and 1-hexanol at 293.15 K and under atmospheric pressure was determined using densimetry and refractometry. The system binodal curve were measured using the cloud point method and the physical properties were correlated with the mass concentrations of the cloudy samples, enabling the quantification of the extract and raffinate phase in the tie-lines measurement. The quantification of the equilibrium phases was satisfactorily obtained using the indirect method, which presented two equations that predicted very well the compositions of the equilibrium phases. The data were precisely correlated by the NRTL model, presenting a mean deviation of 0.61 . The Othmer-Tobias and Hand tests showed high quality data.

\section{REFERENCES}

ALMEIDA, B. F.; WALDRIGUI, T. M.; ALVES, T. C.; OLIVEIRA, L. H.; AZNAR, M. Experimental and calculated liquid-liquid equilibrium data for water + furfural + solvents. Fluid Phase Equilibria, v. 334, p. 97-105, 2012.

BATISTELL, M. C.; ALVES, T. C.; GUADAGNINI, T. R.; OLIVEIRA, L. H.; AZNAR M. (Liquid + liquid) equilibria in \{water + acrylic acid + (1-butanol, or 2-butanol, or 1-pentanol) systems at $\mathrm{T}=293.2 \mathrm{~K}, \mathrm{~T}=303.2 \mathrm{~K}$, and $\mathrm{T}=313.2 \mathrm{~K}$ and atmospheric pressure. $\mathrm{J}$. Chem. Thermodynamics, v. 43, p. 1381-1388, 2011.

GEANKOPLIS, C. J. Transport Processes and Separation Process Principles. New Jersey: Editora Prentice Hall, 2003.

HAND, D. B. Dineric Distribution. J. Phys. Chem., v. 34, p. 1961-2000, 1930.

JUANG, R. S.; HUANG, R. H.; WU, R. T. Separation of citric and lactic acids in aqueous solutions by solvent extraction and liquid membrane processes. J. Membrane Science, v. 136, p. 89-99, 1997.

KUBOTA, F.; MASAHIRO, G. Application of ionic liquids to solvent extraction. Solv. Extraction Research and Development, v. 13, p. 23-36, 2006.

LIU, J.; YUAN, Y.; PAN, Y.; HUANG, Z.; YANG, B. Liquid-liquid equilibrium for systems of glycerol and glycerol tert-butyl ethers. Fluid Phase Equilibria, v. 365, p. 50-57, 2014.

LO, C. T., \& BAIRD, M. H. Solvent Extraction. In R. A. MEYERS, Encyclopedia of Physical Science and Technology. Editora Elsevier Science, 2001. 
OTHMER, D. F.; TOBIAS, P. E. Tie-line Correlation. Ind. and Eng. Chem., v. 34, p. 693-6, 1942.

RENON, H.; PRAUSNITZ, J. M. Local compositions in thermodynamic excess functions for liquid mixtures. AlChe J., v. 14, p. 135-144, 1968.

ROCHA, E. G. A.; FOLLEGATTI, L. A. R.; DUVOISIN, S. J.; AZNAR M. Liquid-liquid equilibria for ternary systems containing ethylic palm oil biodiesel + ethanol + glycerol/water: Experimental data at 298.15 and $323.15 \mathrm{~K}$ and thermodynamic modeling. Fuel, v. 128, p. 356$365,2014$.

RODRIGUES C. E. C.; GONÇALVES C. B.; BATISTA E.; MEIRELlES A. J. A. Deacidification of Vegetable Oils by Solvent Extraction. Recent Patents on Engineering, v. p. 95-102, 2007.

SENOL, A. Phase equilibria for ternary liquid systems of (water + carboxylic acid or alcohol + 1-hexanol) at $\mathrm{T}=293.15 \mathrm{~K}$ : modelling considerations. J. Chem. Thermodynamics, v. 36, p.1007-1014, 2004.

SENOL, A. Liquid-Liquid Equilibria for Mixtures of (Water + Pyruvic Acid + Alcohol/Alamine). Modeling and Optimization of Extraction. J. Chem. Eng. Data, v. 58 p. $528-$ 536, 2013.

STEVENS G. W.; LO, T. C.; BAIRD, M. H. I. Extraction, Liquid-Liquid. In K. OTHMER, Encyclopedia of Chem. Tech., Editora John Wiley \& Sons, 2007.

STOICESCU, C.; IULIAN, O.; SIRBU F. Liquid + Liquid Equilibrium Data for the Ternary Mixtures of 1-Propanol + Water with 1-Butanol, 1-Hexanol, 1-Octanol, or 1-Decanol at 294.15 K. Revue Roumaine de Chimie, v. 53, p. 1117-1123, 2008.

STRAGEVITH, L.; \& D'AVILA, S. G. Application of a Generalized Maximum Likelihood Method in the Reduction of Multicomponent Liquid-Liquid Equilibrium Data. Brazil J. of Chem. Eng., 14, p. 41-52, 1997.

TAHA, M.; TENG, H.; LEE M. Phase diagrams of acetonitrile or (acetone + water + EPPS) buffer phase separation systems at $298.15 \mathrm{~K}$ and quantum chemical modeling. J. Chem. Therm., v. 54, p. 134-141, 2012.

YU, Y. X.; LIU, J. G.; GAO, G. H. Isobaric Vapor-Liquid Equilibria and Excess Volumes for the Binary Mixtures Water + Sulfolane, Water + Tetraethylene Glycol, and Benzene + Tetraethylene Glycol. J. Chem. Eng. Data, 45, p. 570-574, 2000.

Acknowledgements: R Ceriani thanks FAPESP, CNPq and CAPES for financial support and individual grants 